\title{
Online Child Sexual Exploitation Material: A Comparison From Police Data on Men Charged With Child Sexual Exploitation Material Exclusively and Men Charged With Contact Child Sexual Abuse Exclusively
}

\author{
Samuel J. Nicol ${ }^{1}$, Danielle A. Harris ${ }^{1}$, Mark R. Kebbell ${ }^{2}$, James Ogilvie ${ }^{1}$ \\ [1] Griffith Criminology Institute, Griffith University, Mount Gravatt, Queensland, Australia. [2] School of Applied \\ Psychology, Griffith University, Mount Gravatt, Queensland, Australia.
}

Sexual Offending: Theory, Research, and Prevention, 2021, Vol. 16, Article e4301, https://doi.org/10.5964/sotrap.4301

Received: 2020-09-04 • Accepted: 2021-09-08 • Published (VoR): 2021-12-15

Handling Editor: Martin Rettenberger, Centre for Criminology (Kriminologische Zentralstelle - KrimZ), Wiesbaden, Germany

Corresponding Author: Samuel J. Nicol, Griffith Criminology Institute, Griffith University, 176 Messines Ridge Rd, Mount Gravatt, Queensland, 4122, Australia. E-mail: samuel.nicol@griffithuni.edu.au

\begin{abstract}
We do not know whether men who access Child Sexual Exploitation Material (CSEM) are contact child-sex offenders using technology - or a new and different type of child sex offender. This study compares men who were charged with Contact Child Sexual Abuse (CCSA) ( $\mathrm{n}=95)$ exclusively, and men who were charged with offences involving online CSEM $(n=99)$ exclusively. This is the first study of its kind in Australia, the first to divide participants into mutually exclusive offending type groups and to do this using police data. Logistic regression results indicated that CSEM offenders were significantly more likely to be older, more likely to be employed, have fewer criminal charges and supervision violations compared to CCSA offenders. The findings further highlighted the heterogeneity of those charged with child sexual offences based on offence typology. The identification of demographic, lifestyle and interpersonal characteristic differences between online CSEM and CCSA offenders' questions the use of uniform approaches to community supervision and treatment protocols. The implications of these findings are discussed in light of an increased volume of people charged with CSEM offences.
\end{abstract}

\section{Keywords}

child sexual exploitation material (CSEM), child sexual abuse, contact abuse, police data, charged 


\section{Non-Technical Summary}

\section{Background}

Online Child Sexual Exploitation Material (CSEM) has proliferated over the past two decades, but there is still much that we do not know about those who possess it. Because most child sexual abuse remains unreported and undetected, it is important to learn more about the people who access online abuse to better determine their similarities and differences to people charged with Contact Child Sexual Abuse (CCSA).

\section{Why was this study done?}

Prior studies that have compared those convicted of online CSEM offences with those prosecuted for CCSA have shown between-groups differences, but none have compared the groups using police level data in an Australian context. This study also extends beyond the use of 'index offence' as a unit of analysis and includes their entire criminal record. Finally, because this is the first investigation of its kind to examine a contemporary Queensland sample, we can consider the distribution of Indigeneity in both groups.

\section{What we did and found}

This study compared 95 Queensland men charged with CCSA to 99 men charged with online CSEM-related offences in the same jurisdiction. This study concluded that those charged with CCSA were more likely than those arrested for CSEM offences to be younger, Indigenous, unemployed, have prior criminal charges, and previous community order breaches.

\section{What do these findings mean?}

This study compared men who had come to the attention of police for CSEM exclusively with men who had come to the attention of police for CCSA exclusively. A relatively clear picture of two distinct profiles emerged from these results: those charged with CCSA were younger, more likely to be Indigenous and often with antisocial indicators such as prior criminal charges and supervision violations. Conversely, those charged with CSEM offences were often lacking antisocial indicators, more likely to be employed and appeared to have less direct access to children than the CCSA cohort. The findings from this study are consistent with comparative research on convicted offender groups from other jurisdictions (e.g., Babchishin et al., 2015; Faust et al., 2015). 


\section{Highlights}

- CSEM offenders were significantly older than CCSA offenders and less likely to be Indigenous.

- CCSA offenders were more likely than CSEM offenders to present with an antisocial orientation including more prior offending and supervision violations.

- Lifestyle factors also differentiated the groups significantly. CCSA offenders were more likely to be residing with a child at the time of their offence and less likely to be employed than the CSEM offenders. Long term relationship status did not significantly differ between the groups.

Online child sexual exploitation material (CSEM) offences continue to be a considerable challenge for law enforcement. The number of investigations into CSEM has continued to increase in many international jurisdictions (Eke et al., 2011; Elliott et al., 2009; Jung et al., 2013; Merdian et al., 2009). In twenty years of operation, the National Center for Missing and Exploited Children (NCMEC, 2019) (USA), received 45.2 million reports of suspected CSEM, with more than half of these occurring in the last two years. In March 2018, the Australian government committed \$68.6 million to establish the Australian Centre to Counter Child Exploitation (ACCCE, 2019) as a coordinated federal response to countering the increasing prevalence of online CSEM. In the 2019-2020 financial year, the ACCCE received 21,688 reports of CSEM. This was a $50 \%$ increase on the previous 14,165 reports from the previous financial year (Australian Federal Police [AFP], 2020). Self-report surveys and increased identification of CSEM access through peer-to-peer (P2P) networks have further highlighted the prevalence of CSEM (Babchishin et al., 2018; Seto et al., 2015). Fortunately, most people charged with CSEM offences are successfully prosecuted (Wolak et al., 2011).

Few research studies of this cohort have come exclusively from police holdings. Since the advent of sexual offender registration, police often hold some responsibility for assessing risk and community supervision for those charged, but not yet prosecuted for child sexual abuse. The knowledge derived from these data will assist police in assessing risk and classifying offenders to direct operational resources. Much remains unknown about people adjudicated for these crimes exclusively and particularly how, if at all, they differ from offenders adjudicated for CCSA. Prior studies have identified important differences between CSEM and CCSA offenders.

\section{Child Sexual Exploitation Material (CSEM)}

Prior to the Internet, viewing, collecting or distributing CSEM was an arduous task. Access to CSEM would require a person to conduct manual searches of classified advertisements, produce their own CSEM through contact offending, or produce their own discreet video footage of children (Seto, 2013). The Internet has not only enabled greater 
access to CSEM and online grooming but has presented greater opportunities for virtual networks of offenders to be established (Beech et al., 2008). The Internet and increased use of mobile technology has shifted the access of CSEM from a relatively high risk of detection to a much lower risk of detection. This low detection rate is partly due to the relative anonymity available through the use of encryption, virtual private networks (VPN), or the DarkWeb. Simultaneously, the sheer volume of CSEM being produced has grown and the number of people accessing this material has increased. Such a high volume of activity in a global criminal market presents serious challenges for police in identifying offenders and victims in multiple jurisdictions from around the world. From an investigative perspective, detection for CSEM offences is often not reliant upon victim disclosure but through electronic identification of Internet Protocol (IP) addresses linked to CSEM. Consequently, the characteristics of those people who are convicted for CCSA could differ markedly from those convicted for CSEM offences (Babchishin et al., 2015; Brown \& Bricknell, 2018; Clevenger et al., 2016; Eke et al., 2011; Faust et al., 2015; Houtepen et al., 2014; McManus et al., 2015). Although it is recognised that there are a broad range of online CSEM offence types, this study focuses on men (over 18 years) charged for possessing or distributing CSEM in which their offending did not involve an attempt to contact a child in a real or virtual environment.

Research suggests that paedophilia is often a primary (but not exclusive) driver for downloading and viewing CSEM by adult men (Seto, 2013). Studies estimate that approximately $2-4 \%$ of men in the general population have viewed CSEM online, which is consistent with the estimated rates of paedophilia amongst men (Seto, 2013). Studies that include phallometric testing have shown that physiological responses to sexual images of children are more common amongst CSEM offenders than other types of sexual offenders and non-offending men. Seto et al. (2006) conducted research on 685 participants, including offenders charged with CSEM offences, CCSA, sexual offences against adults (17 years and above) and people with no history of sexual offending. The results showed that the offenders who were known to have CSEM offences were significantly more likely to have paedophilic sexual arousal on phallometric testing than the other groups included in the sample (Seto et al., 2006).

\section{Differences Between CSEM and CCSA Offending}

Prior studies have shown men convicted for CSEM offences differ markedly from those convicted for CCSA across several domains including socio-demographic, psychosocial, criminological, and psychological (Henshaw et al., 2017). No prior studies have been based upon Queensland data, which is particularly relevant when considering the higher Indigenous population within the State. One in four people in Australia who identify as Aboriginal reside in Queensland and nearly two thirds of all Torres Strait Islander people in Australia live in Queensland (Queensland Government Statistician's Office [QGSO], 2016). ${ }^{1}$ When compared to non-Indigenous populations, Indigenous Australians have 
higher rates of single parent families, lower rates of employment, different employment types, and lower levels of high school completions (QGSO, 2016). These, and many other factors contribute to Indigenous Australians being overrepresented as both offenders and victims in the criminal justice system, including for sexual offending (Gathercole et al., 2016). Despite this, there is limited research including Indigenous Australians in comparative analysis of CCSA and CSEM offending. Other demographic and lifestyle factors such as age, employment and educational attainment have been included in prior studies.

Research findings suggest that, on average, CSEM offenders are almost exclusively male, Caucasian, in their late-30s to mid-40s, employed, and well educated (Aslan \& Edelmann, 2014; Babchishin et al., 2015; Brown \& Bricknell, 2018; Clevenger et al., 2016; Faust et al., 2015; Henshaw et al., 2017; Jung et al., 2013; Merdian et al., 2009). People convicted of CSEM offences are also less likely to be in a long-term relationship (Babchishin et al., 2015). It could follow then that fewer (or shorter) relationships might be less likely to include a child and thus reduced access to children results in fewer opportunities to perpetrate CCSA.

Other studies have examined developmental or cognitive differences between online CSEM offenders and those who perpetrate CCSA. Jung et al. (2013) identified online CSEM offenders as having had fewer childhood behavioural problems than comparative groups of contact and non-contact child sexual offenders. Babchishin et al.'s (2015) meta-analysis concluded that CCSA offenders were also more likely to report Adverse Childhood Experiences (ACEs) including family disruption, conduct problems, and both physical and sexual abuse, when compared with CSEM offenders. They also concluded that CSEM offenders generally exhibit lower levels of self-esteem and assertiveness compared to CCSA offenders (see also: Henshaw et al., 2017). A final point of difference between CCSA and CSEM offenders is atypical sexual interest. Research indicates that CSEM offenders report high levels of atypical sexual interest, including paedophilia, sexual pre-occupation, and use of sex as a coping mechanism than CCSA offenders (Babchishin et al., 2015; Henshaw et al., 2017; Seto, 2013).

The suggestion that pornography is a precursor to contact offending dates back before the proliferation of the Internet and has long been theorised in academic literature (Marshall, 2000). The question of whether people who access CSEM go on to commit a 'hands-on' contact sexual offence is nuanced and the research is fraught with definitional variation. Some have argued that continued CSEM exposure validates abuse-supportive attitudes, making CCSA more likely (Bourke \& Hernandez, 2009), whereas others consider it likely a substitute for CCSA (Riegel, 2004). With so much CSEM remaining undetected, the propensity for escalation from CSEM to CCSA remains a source of

1) In the remainder of this article, we respectfully refer to all Aboriginal and Torres Strait Islander Peoples as Indigenous Australians. 
debate. Eke et al. (2011) conducted a study consisting of 541 men convicted for CSEM offences in which $30 \%$ were identified as having had contact with police for previous CCSA (Henshaw et al., 2017). More than twice as many participants were known to have committed CCSA prior to (18\%), rather than after (8\%) their arrest for the CSEM offence (Eke et al., 2011). Only 3.9\% of the CSEM offenders in this study were detected for CCSA within the 5.9 years following their CSEM arrest. This is consistent with other studies which found the reoffending rate was approximately $4.6 \%$, with only $2 \%$ committing a subsequent CCSA offence within six years (Seto et al., 2011).

Rates of reconviction for CCSA are approximately 10-15\% (Hanson \& Harris, 1998), but the rates of reoffending amongst 'CSEM only' offenders is reportedly much lower (Seto, 2013). In recognition of the different characteristics associated with perpetrators of online CSEM compared to CCSA, Seto and Eke (2015) developed the Child Pornography Offender Risk Tool (CPORT). The CPORT items include: 1) offender age at time of index sexual offence; 2) prior criminal record; 3) prior CCSA offence; 4) failure on prior conditional release; 5) indication of paedophilic or hebephilic interest; 6) ratio of boys to girls in CSEM; and 7) ratio of boy to girl nudity and other child contact (Seto \& Eke, 2015). The CPORT has been validated with good predictive accuracy for recidivism amongst CSEM offenders (AUC $=.74$ ) and sexual recidivism more broadly (AUC $=.72$ ) (Eke et al., 2019).

\section{Present Study}

The current study identified and compared two groups: men charged with offences involving the possession or distribution of CSEM exclusively, and men charged with CCSA exclusively. Men were included exclusively because of a lack of women charged with relevant offences to enable meaningful analysis. The groups were then compared on demographic variables and several items common across extant actuarial risk assessment tools. Data were collected in Queensland, exclusively at the point of charge from police holdings. This study addresses the following research questions:

1. Are there meaningful differences between those charged exclusively with online CSEM offences and those charged exclusively with CCSA?

2. How do these differences compare with prior studies of convicted offenders?

When compared to individuals charged with CSEM, it is hypothesised, based on the findings from prior comparative studies, that individuals charged with CCSA will be more likely to; 1 ) be younger; 2 ) be Indigenous; 3 ) have prior criminal charges and supervision violations; 4) have a history of problematic alcohol or illicit drug use; 5) be single or not to have been in a long term relationship; 6) have convenient access to children, and; 7) be unemployed. 


\title{
Method
}

\section{Data Source and Participants}

Administrative data on 194 men were collected from the Queensland Police Service (QPS). The sample includes men exclusively, due to the very small number of women charged with child sexual offences available within the main QPS database. To create a contemporary sample, cases were prioritised by recency (descending date order from the present). Cases were assigned to one of two groups: those charged exclusively with CSEM offences $(n=99)$ and those charged exclusively with CCSA offences $(n=95)$. All participants' available prior criminal records and police holdings were checked to ensure that no crossover or mixed cases were included. That is, men who were allocated to the CCSA group, for example, had no record of any convictions, charges or allegations relating to CSEM and vice versa.

\section{Measures}

A range of measures were used to compare the two groups. These variables were initially derived from prior research (Babchishin et al., 2015; Henshaw et al., 2017) and inclusion criteria were ultimately based upon their availability for accurate coding across cases. Each of the included variables are described and explained below.

\begin{abstract}
Age
Age of offender was measured in years. In the present study, age was operationalised as the known onset of the index sexual offence. We note that this is distinct from other risk assessment tools such as the CPORT (Seto \& Eke, 2015) and the Risk Matrix 2000 (RM2000) (Thornton, 2007) where age is measured at the start of the investigation or at the point of release (respectively).
\end{abstract}

\section{Ethnicity}

Ethnicity was dichotomised as Indigenous/ Non-Indigenous. Subjects who self-identified as Aboriginal and/or Torres Strait Islander (ATSI) were recorded as such within these data regardless of other recorded ethnicities. This approach was utilised to overcome the issue of multiple ethnicities recorded in police holdings and is a unique measure for comparative studies of this nature.

\section{Employment}

Employment status was categorised as employed or unemployed at the time of arrest for the child sexual offence arrest. If the subject was in any form of full-time or part-time employment, they were categorised as employed. Subjects who were known to be retired were excluded from analysis for this variable $(n=11)$. Employment has been identified as 
an important protective factor against CCSA (Robbé et al., 2015), whereas unemployment can be an indicator of a higher likelihood of antisocial orientation and impulsivity (Hanson \& Harris, 1998; Hanson \& Morton-Bourgon, 2005).

\section{Long-Term Relationship}

Long-term relationship referred to the individual's known relationship status up to the time of the commission of the sexual offence. A long-term relationship was endorsed if the subject was either 1) married; or 2) in a de-facto/common-law relationship. A de-facto/common-law relationship includes if they had been cohabiting for at least two years or if there was available information that they had been in a consistent intimate relationship for at least a two-year period prior to the offence. Although prior comparative studies (Babchishin et al., 2015) and actuarial tools such as the Risk Matrix 2000 (Thornton, 2007) endorse this item by its presence throughout the life course, accurate information at that level of detail about relationships after the point of arrest was not available from the present data. We note that our results on this variable can therefore not be compared directly with the above studies.

\section{Residing With Child/ren}

This was operationalised as whether any available information suggested the subject was residing in the same household as anyone under the age of 16 years at the time of the child sexual offence, regardless of whether the child was a victim of the subject's offences. Situational factors, such as unsupervised access to children is a significant predictor of CCSA (Leclerc et al., 2015) and therefore, an important measure in this comparative analysis.

\section{Criminal Charge History}

This was dichotomised as present or absent and indicated whether the person had recorded criminal charges (for any offence type) in Queensland prior to the charges for the child sexual offence. These charges included any offences which, should they lead to a conviction, could result in a custodial or community supervision sentence. Minor driving infringements such as speeding, or parking offences are therefore not included. This is consistent with the scoring of common actuarial risk assessments tools such as the Risk Matrix 2000 (Thornton, 2007).

\section{Supervision Violations}

Supervision violations include breaches of community-based orders, breaches of bail, failing to comply with reporting obligations or any other breach of a community order. "Supervision violations" was recorded as a dichotomous variable and was limited to the jurisdiction of Queensland. Such violations needed to have occurred prior to their arrest for the sexual offence and could include community-based orders not necessarily 
constituting a criminal offence. Supervision violations has been identified as indicative of an antisocial orientation and a significant predictor of sexual recidivism (Hanson \& Morton-Bourgon, 2005).

\section{Substance Use}

Drug and alcohol abuse were also measured as a dichotomous variable (measured prior to the arrest for the sexual offence). It should be noted that this variable was intended to determine problematic addictive alcohol usage or illicit drug usage only. The alcohol usage indicator was endorsed in cases where the offence description, intelligence holdings, or flag on police holdings indicated that the alcohol usage was of an addictive nature prior to the relevant arrest, such as repeatedly recorded incidents involving alcohol, or recorded for offences such as driving under the influence of alcohol. Further, the indicator of drug usage refers to illicit drug use only. This included any recorded history of this nature on the police holdings database. Substance abuse has been established as a predictor of an antisocial orientation and significantly correlated to the perpetration of CCSA (Wilpert et al., 2018) and so included as an important measure of comparison for CSEM offenders.

\section{Analytical Strategy}

Chi-square tests for independence were used to analyse each of the categorical variables to determine between-groups differences based on the outcome variables (group membership; CSEM or CCSA). The assumptions of the test were upheld in each case, with no more than $25 \%$ of cells in each of the contingency tables having an expected frequency of less than 5 , and observations were independent. ${ }^{2}$ Age was the only continuous variable, so an independent sample $t$-test was conducted to compare the mean average age of both the CSEM and CCSA cohorts. A logistic regression was then conducted to determine the incremental accuracy of the predictor variables. These data were checked for the presence of multivariate outliers by calculating Mahalanobis and Cook's distances and no cases required removal. The assumptions of normality, linearity, and homoscedasticity were satisfied.

2) Consistent with prior research in the behavioural sciences, the effect size threshold for Cramer's $V$ was set at: Small $=.01$, Moderate $=.30$, and large $=.50($ Pallant, 2020). 


\section{Results}

\section{Univariate Analysis}

The variables are grouped into three categories: 1) demographics; 2) lifestyle factors; and 3) antisocial and criminal indicators. Table 1 provides the descriptive and inferential analyses with further explanation provided in the following sections.

\section{Demographic Variables}

As predicted by hypotheses 1 and 2, those charged with CCSA were younger and more likely to be Indigenous Australians than those charged with CSEM offences.

\section{Table 1}

Chi-Squared Analysis of Differences Between Persons Charged With CSEM Offences Compared to Persons Charged With CCSA

\begin{tabular}{|c|c|c|c|c|c|}
\hline Item & $\begin{array}{c}\text { CSEM } \\
(n)\end{array}$ & $\begin{array}{c}\text { CCSA } \\
(n)\end{array}$ & $\chi^{2}$ & $d f$ & Cramer's V \\
\hline Indigenous Status & 99 & 95 & $13.99^{* * *}$ & 1 & .27 \\
\hline Indigenous & 1 & 15 & & & \\
\hline Non-Indigenous & 98 & 80 & & & \\
\hline Employment & 95 & 88 & $12.48^{* * *}$ & 1 & .26 \\
\hline Employed & 76 & 49 & & & \\
\hline Unemployed & 19 & 39 & & & \\
\hline Prior Criminal charges & 99 & 95 & $18.49^{* * *}$ & 1 & .31 \\
\hline Prior charges & 32 & 60 & & & \\
\hline No charges & 67 & 35 & & & \\
\hline Supervision violations & 99 & 95 & $29.52^{* * *}$ & 1 & .39 \\
\hline Prior supervision violations & 14 & 48 & & & \\
\hline No supervision violations & 85 & 47 & & & \\
\hline Substance abuse & 98 & 95 & 1.83 & 1 & .10 \\
\hline Residing with Child/ren & 94 & 85 & $8.18^{* *}$ & 1 & .21 \\
\hline Residing with child/ren & 22 & 37 & & & \\
\hline Not residing with child/ren & 72 & 48 & & & \\
\hline Long Term relationship & 86 & 85 & 0.70 & 1 & .06 \\
\hline
\end{tabular}

The CSEM offenders were an average of seven years older than the CCSA group, 7.55 years; 95\% CI $[3.84,11.26] ; d=0.58$. The CSEM group had an average age of 41.74 years $(S D=13.09)$ and the CCSA group had an average age of 34.19 years $(S D=13.13)$, $t(192)=4.01, p<.001$. Indigenous Australians were overrepresented in the CCSA group 
(15.8\%) compared to only 1 person in the CSEM group, $\chi^{2}(1, n=194)=13.99, p<.001$.

To contextualize these percentages, Indigenous people account for approximately $4.6 \%$ of the Queensland population (Australian Bureau of Statistics, 2018) but 15.8\% of the CCSA group.

\section{Antisocial and Criminal Indicators}

Overall, a considerable number of participants revealed problematic substance use (Hypothesis 4), criminal charges, and supervision violations (Hypothesis 3) but only the difference between the latter two comparisons were statistically significant. As predicted in Hypothesis 3, those charged with CCSA were more likely than those charged with CSEM to have other criminal charges, $\chi^{2}(1, n=194)=18.49, p<.001$, and supervision violations, $\chi^{2}(1, n=194)=29.52, p<.001$, prior to their arrest.

\section{Lifestyle Variables}

Hypotheses 6 was supported, with the CCSA group more likely than the CSEM group to have access to children at the time of their offence $\left(\chi^{2}(1, n=179)=8.18, p<.01\right)$. Finally, Hypothesis 7 was also supported with the observation of a statistically significant difference between the groups on employment. CCSA offenders were less likely to be employed, $\chi^{2}(1, n=183)=12.48, p<.001$, at the time of their offence than their CSEM counterparts.

\section{Multivariate Analysis}

The dependent variable in the multivariate analysis was group membership. Due to missing data, the final regression model included 153 subjects ( 81 online CSEM and 72 CCSA). The regression model also excluded Indigenous status due to complete separation on that item. The full model was statistically significant, $\chi^{2}(7, N=153)=48.626, p<.001$, indicating the model was able to distinguish between the groups based on variables other than their index arrest. All variables included in the model accounted for between 27.2\% (Cox and Snell R squared) and 36.3\% (Nagelkerke R squared) of the variance and correctly classified $75.2 \%$ of cases. At the multivariate level, age (Wald $=4.215, p<.05$ ), unemployment (Wald $=4.465, p<.05)$, prior criminal charges (Wald $=4.746, p<.05$ ), and previous supervision violations (Wald $=7.322, p<.01$ ) were statistically significant (see Table 2). 
Table 2

Logistic Regression Predicting Likelihood of CCSA Rather Than CSEM Offences $(N=129)$

\begin{tabular}{lcccc}
\hline Item & $\boldsymbol{\beta}$ & Odds Ratio & $\boldsymbol{L} \boldsymbol{L}$ & $\boldsymbol{U}$ \\
\hline Age & -.032 & $.968^{*}$ & 0.939 & 0.999 \\
Employment & -.953 & $.386^{*}$ & 0.159 & 0.933 \\
Prior QLD criminal charges & 0.973 & $2.646^{*}$ & 1.103 & 6.348 \\
Prior supervision violations & 1.368 & $3.927^{* *}$ & 1.458 & 10.577 \\
Substance abuse & -0.347 & .707 & .299 & 1.668 \\
Residing with child/ren & 0.700 & 2.013 & 0.812 & 4.988 \\
Long term relationship & 0.934 & 2.544 & .989 & 6.544 \\
\hline${ }^{*} p<.0 .^{* *} p<.01$. & & & &
\end{tabular}

${ }^{*} p<.05 .{ }^{* *} p<.01$.

\section{Discussion}

This study compared men who had come to the attention of police for CSEM exclusively with men who had come to the attention of police for CCSA exclusively. A relatively clear picture of two distinct profiles emerged from these results: those charged with CCSA were younger, more likely to be Indigenous and often with antisocial indicators such as prior criminal charges and supervision violations. Conversely, those charged with CSEM offences were often lacking antisocial indicators, more likely to be employed and appeared to have less direct access to children than the CCSA cohort. The findings from this study are consistent with comparative research on convicted offender groups from other jurisdictions (Babchishin et al., 2015; Faust et al., 2015).

This study identified demographic differences between the two groups. Firstly, in support of Hypothesis 1, those charged with CCSA were younger than those charged with CSEM. Being younger, is often associated with a higher risk of sexual recidivism (Tully \& Browne, 2015), but limitations exist for coding this variable amongst people charged with CSEM exclusively because in most CCSA offences, there is a survivor and/or witness who can attest to the start of the offending, but this is rarely the case with CSEM offences. Investigations for CSEM offences are often reliant upon police identification, or through subsequent digital forensic evidence. The second demographic difference relates to the higher proportion of Indigenous men in the CCSA group compared to the CSEM group (Hypothesis 2). The higher rates of Indigenous people in the CCSA offender group are reflective of Indigenous overrepresentation in the criminal justice system more broadly. The reasons for these findings are multifactorial but include substantial disadvantage experienced within Indigenous communities contributing to higher rates of criminal offending and victimisation when compared to Non-Indigenous Australians. Restricted access to the Internet through fewer technological devices in Indigenous communities can explain less Indigenous representation in the CSEM group, 
but this may change as mobile technology and the Internet become more accessible to remote communities. Further research is required to confirm this disparity and identify causal factors for it.

This study also confirmed Hypotheses 3 (prior criminal charges) and 4 (supervision violations) that indicators of an antisocial orientation were more prevalent amongst the CCSA group than the CSEM group. This suggests that for a significant proportion of people, CCSA may be an extension of their general antisocial behaviour. Their antisocial traits may increase their propensity of engaging in sexual acts with inappropriate partners, including children, and less likely to inhibit sexual impulses. Conversely, with such high rates of undetected CCSA, these findings could also point to the higher likelihood of detection for CCSA should a person have antisocial traits. Impulsivity and a lack of planning in their CCSA would mean they're less likely to evade detection for their crimes. CSEM offenders may be better able to plan offences through other means, such as through the internet. Perhaps, as outlined by Elliott et al. (2009), there are other important etiological factors associated with those offenders who access CSEM.

In contrast to Hypothesis 5, the group were not distinguished by prior long-term relationships. The explanation for the two groups not being differentiated by prevalence of long-term relationships is unclear, but it is conceivable that each participant's capability to maintain a long-term relationship depends on several variables. One possible explanation might be an inability to maintain a lasting relationship due to a highly impulsive personality with a lack of self-control and antisocial orientation. Another explanation might be that excessive Internet usage is indicative of social isolation and lack of opportunity to find a suitable partner. Conversely, the breakdown of short-term relationships or lack of relationships may have contributed to their offending in different ways across the different offence categories (CCSA and CSEM). Further research including of a qualitative nature is, therefore, recommended before drawing such conclusions.

\section{Limitations}

Whilst utilising data held exclusively at a police (arrest) level was central to the contribution of this study, there are limitations in this approach. Although police have increased their responsibility for crime prevention strategies and community supervision since the use of sexual offender registration, they do not do this in isolation. When assessing risk, information is shared between government agencies to formulate a more complete picture of the person under observation. Information from police holdings on criminal offending, antisocial behaviours, and details of sexual offending, including CSEM collections, is as abundant as that held by any other agency. Having said that, they are probably not the best source of information for lifestyle factors including relationships, employment, housing, and history of substance abuse. It should also, therefore, be noted that if an item was not endorsed, this does not mean it was necessarily absent or irrelevant, only that there were no available indicators of its presence from the holdings. There 
are a range of psychological characteristics which could not be coded or included in this study. This is a clear limitation with respect to comparing results to those derived from studies that have used actuarial risk assessment and would add depth to the comparative findings. Broadening the scope of data source and methodology used for this study does, however, raise some questions regarding information collected by government agencies and their efficacy for identifying needs in community supervision.

Further, it is noted that there are limitations in coding CSEM risk variables exclusively from police holdings. For example, it was not possible to code some of the CPORT items from these records alone. Technological advancements, including file retention capabilities, have resulted in offender CSEM collections becoming much more extensive, making reliable evaluation of imagery problematic for police. Additionally, CSEM may be used as a commodity to exchange within networks, further questioning the efficacy of coding variables based upon CSEM content for identifying atypical sexual interest of individuals.

The sample groups were heterogenous, presenting an additional limitation. An example is the range of behavioural characteristics that constitute CCSA. There is value in further research exploring these potential differences and addressing those differential implications for comparative analysis. Missing data from the logistic regression model represented a further limitation of analysis. There were 41 missing cases in the regression model accounting for $21 \%$ of the original sample which could invalidate some of the results. This was somewhat overcome through the relative proportional distribution of subjects between the groups with 18 missing cases from the online CSEM group and 23 from the CCSA group. Finally, not including a group that had both CCSA and CSEM offences could be viewed as a limitation, but also a topic for future research.

\section{Conclusion}

This study compared those charged with online CSEM offences exclusively with those charged with CCSA exclusively. This makes a unique contribution to research by including only those identified with CSEM or CCSA offences across the entirety of their criminal record, using police holdings. Due to the data source, participants in this study were assigned from the point of charge rather than conviction. With police's increased responsibility in community supervision of CSEM offenders through sexual offender registration, this study identified that prosecution bias was not present and that those charged with CSEM offences differed in significant ways to those charged with CCSA. These include demographic factors such as age and Indigenous status, antisocial indicators such as prior criminal charges and supervision violations, and lifestyle factors including employment and whether they were residing with a child at the time of arrest. Age, employment, prior criminal charges and supervision violations were also significant at the multivariate level. Research into people charged with CSEM offences is 
still emerging, and these findings highlight characteristic differences between them and CCSA offenders in an Australian context.

Funding: The authors have no funding to report.

Acknowledgments: The authors wish to acknowledge the support and assistance from the Queensland Police Service in undertaking this research. The views expressed in this publication are not necessarily those of the Queensland Police Service and any errors of omission or commission are the responsibility of the authors.

Competing Interests: The authors have declared that no competing interests exist.

Twitter Accounts: @SamuelNicol7

Data Availability: Data for this study can be made available by contacting the corresponding author.

\section{References}

Aslan, D., \& Edelmann, R. (2014). Demographic and offence characteristics: A comparison of sex offenders convicted of possessing indecent images of children, committing contact sex offences or both offences. Fournal of Forensic Psychiatry \& Psychology, 25(2), 121-134. https://doi.org/10.1080/14789949.2014.884618

Australian Bureau of Statistics. (2018). Estimates of Aboriginal and Torres Strait Islander Australians. https://www.abs.gov.au/statistics/people/aboriginal-and-torres-strait-islander-peoples/ estimates-aboriginal-and-torres-strait-islander-australians/latest-release

Australian Centre to Counter Child Exploitation. (2019). Blueprint 2019-2021. Australian Federal Police. https://www.acce.gov.au/sites/default/files/2020-12/ACCCE\%20Blueprint\%2020 19-2021_online.pdf

Australian Federal Police. (2020). Predators exploiting kids online during virus second wave. https://www.afp.gov.au/news-media/media-releases/predators-exploiting-kids-online-duringvirus-second-wave

Babchishin, K. M., Hanson, R. K., \& VanZuylen, H. (2015). Online child pornography offenders are different: A meta-analysis of the characteristics of online and offline sex offenders against children. Archives of Sexual Behavior, 44(1), 45-66. https://doi.org/10.1007/s10508-014-0270-x

Babchishin, K. M., Merdian, H. L., Bartels, R. M., \& Perkins, D. (2018). Child sexual exploitation materials offenders: A review. European Psychologist, 23(2), 130-143.

https://doi.org/10.1027/1016-9040/a000326

Beech, A. R., Elliott, I. A., Birgden, A., \& Findlater, D. (2008). The internet and child sexual offending: A criminological review. Aggression and Violent Behavior, 13(3), 216-228. https://doi.org/10.1016/j.avb.2008.03.007 
Bourke, M. L., \& Hernandez, A. E. (2009). The 'Butner study' redux: A report of the incidence of hands-on child victimization by child pornography offenders. fournal of Family Violence, 24(3), 183-191. https://doi.org/10.1007/s10896-008-9219-y

Brown, R., \& Bricknell, S. (2018). What is the profile of child exploitation material offenders? (No. 564). Australian Institute of Criminology. https://www.aic.gov.au/publications/tandi/tandi564

Clevenger, S. L., Navarro, J. N., \& Jasinski, J. L. (2016). A matter of low self-control? Exploring differences between child pornography possessors and child pornography producers/ distributers using self-control theory. Sexual Abuse, 28(6), 555-571. https://doi.org/10.1177/1079063214557173

Eke, A. W., Helmus, L. M., \& Seto, M. C. (2019). A validation study of the child pornography offender risk tool (CPORT). Sexual Abuse, 31(4), 456-476. https://doi.org/10.1177/1079063218762434

Eke, A. W., Seto, M. C., \& Williams, J. (2011). Examining the criminal history and future offending of child pornography offenders: An extended prospective follow-up study. Law and Human Behavior, 35(6), 466-478. https://doi.org/10.1007/s10979-010-9252-2

Elliott, I. A., Beech, A. R., Mandeville-Norden, R., \& Hayes, E. (2009). Psychological profiles of internet sexual offenders: Comparisons with contact sexual offenders. Sexual Abuse, 21(1), 76-92. https://doi.org/10.1177/1079063208326929

Faust, E., Bickart, W., Renaud, C., \& Camp, S. (2015). Child pornography possessors and child contact sex offenders: A multilevel comparison of demographic characteristics and rates of recidivism. Sexual Abuse, 27(5), 460-478. https://doi.org/10.1177/1079063214521469

Gathercole, M. F., Lykins, A. D., \& Dunstan, D. A. (2016). Identifying key pathways into sexual offending for juvenile offenders and exploring possible differences for the Aboriginal community. Sexual Abuse in Australia and New Zealand, 7(1), 18-30.

Hanson, R. K., \& Harris, A. J. (1998). Dynamic predictors of sexual recidivism. Department of the Solicitor General of Canada. http://www.static99.org/pdfdocs/hansonandharris1998.pdf

Hanson, R. K., \& Morton-Bourgon, K. E. (2005). The characteristics of persistent sexual offenders: A meta-analysis of recidivism studies. Journal of Consulting and Clinical Psychology, 73(6), 1154-1163. https://doi.org/10.1037/0022-006X.73.6.1154

Henshaw, M., Ogloff, J. R. P., \& Clough, J. A. (2017). Looking beyond the screen: A critical review of the literature on the online child pornography offender. Sexual Abuse, 29(5), 416-445. https://doi.org/10.1177/1079063215603690

Houtepen, J. A. B. M., Sijtsema, J. J., \& Bogaerts, S. (2014). From child pornography offending to child sexual abuse: A review of child pornography offender characteristics and risks for crossover. Aggression and Violent Behavior, 19(5), 466-473. https://doi.org/10.1016/j.avb.2014.07.011

Jung, S., Ennis, L., Stein, S., Choy, A. L., \& Hook, T. (2013). Child pornography possessors: Comparisons and contrasts with contact and non-contact sex offenders. Fournal of Sexual Aggression, 19(3), 295-310. https://doi.org/10.1080/13552600.2012.741267 
Leclerc, B., Smallbone, S., \& Wortley, R. (2015). Prevention nearby: The influence of the presence of a potential guardian on the severity of child sexual abuse. Sexual Abuse, 27(2), 189-204. https://doi.org/10.1177/1079063213504594

Marshall, W. L. (2000). Revisiting the use of pornography by sexual offenders: Implications for theory and practice. fournal of Sexual Aggression, 6(1-2), 67-77. https://doi.org/10.1080/13552600008413310

McManus, M. A., Long, M. L., Alison, L., \& Almond, L. (2015). Factors associated with contact child sexual abuse in a sample of indecent image offenders. fournal of Sexual Aggression, 21(3), 368-384. https://doi.org/10.1080/13552600.2014.927009

Merdian, H. L., Wilson, N., \& Boer, D. P. (2009). Characteristics of internet sexual offenders: A review. Sexual Abuse in Australia and New Zealand, 2(1), 34-47.

National Center for Missing and Exploited Children. (2019). Child sexual exploitation reports explode. https://www.missingkids.org/blog/2019/pre-update/cse-reports-explode

Pallant, J. (2020). SPSS survival manual: A step by step guide to data analysis using IBM SPSS (7th ed.). Allen \& Unwin.

Queensland Government Statistician's Office. (2016). Aboriginal and Torres Strait Islander peoples in Queensland, Census 2016. Queensland Government.

https://www.qgso.qld.gov.au/issues/2796/aboriginal-torres-strait-islander-peoples-qldcensus-2016.pdf

Riegel, D. L. (2004). Effects on boy-attracted pedosexual males of viewing boy erotica. Archives of Sexual Behavior, 33(4), 321-323. https://doi.org/10.1023/B:ASEB.0000029071.89455.53

Robbé, M. V., Mann, R. E., Maruna, S., \& Thornton, D. (2015). An exploration of protective factors supporting desistance from sexual offending. Sexual Abuse, 27(1), 16-33.

https://doi.org/10.1177/1079063214547582

Seto, M. C. (2013). Internet sex offenders. American Psychological Association. https://doi.org/10.1037/14191-000https://doi.org/10.1037/14191-000

Seto, M. C., Cantor, J. M., \& Blanchard, R. (2006). Child pornography offenses are a valid diagnostic indicator of pedophilia. Journal of Abnormal Psychology, 115(3), 610-615. https://doi.org/10.1037/0021-843X.115.3.610

Seto, M. C., \& Eke, A. W. (2015). Predicting recidivism among adult male child pornography offenders: Development of the child pornography offender risk tool (CPORT). Law and Human Behavior, 39(4), 416-429. https://doi.org/10.1037/lhb0000128

Seto, M. C., Hanson, R. K., \& Babchishin, K. M. (2011). Contact sexual offending by men with online sexual offenses. Sexual Abuse, 23(1), 124-145. https://doi.org/10.1177/1079063210369013

Seto, M. C., Hermann, C. A., Kjellgren, C., Priebe, G., Svedin, C. G., \& Långström, N. (2015).

Viewing child pornography: Prevalence and correlates in a representative community sample of young Swedish men. Archives of Sexual Behavior, 44(1), 67-79.

https://doi.org/10.1007/s10508-013-0244-4

Thornton, D. (2007). Scoring guide for risk matrix 2000.9/SVC.

https://www.birmingham.ac.uk/Documents/college-les/psych/RM2000scoringinstructions.pdf 
Tully, R. J., \& Browne, K. D. (2015). Appraising the Risk Matrix 2000 static sex offender risk assessment tool. International fournal of Offender Therapy and Comparative Criminology, 59(2), 211-224. https://doi.org/10.1177/0306624X13508928

Wilpert, J., van Horn, J. E., \& Boonmann, C. (2018). Comparing the central eight risk factors: Do they differ across age groups of sex offenders? International fournal of Offender Therapy and Comparative Criminology, 62(13), 4278-4294. https://doi.org/10.1177/0306624X18758899

Wolak, J., Finkelhor, D., \& Mitchell, K. (2011). Child pornography possessors: Trends in offender and case characteristics. Sexual Abuse, 23(1), 22-42. https://doi.org/10.1177/1079063210372143

IATSO=-

International Association for the
Ireatment of Sexual Offenders

Sexual Offending: Theory, Research, and Prevention (SOTRAP) is the official journal of the International Association for the Treatment of Sexual Offenders (IATSO).
(P) leibniz-psychology.org

PsychOpen GOLD is a publishing service by Leibniz Institute for Psychology (ZPID), Germany. 